\title{
Effect of extrinsic denervation on the rate of net water transport of the feline gall bladder
}

\author{
S BJÖRCK, H AHLMAN, AND A DAHLSTRÖM \\ From the Department of Surgery I and III, and Institute of Neurobiology, University of Göteborg, \\ Göteborg, Sweden
}

SUMmaRY The influence on the concentrating ability of the gall bladder after extrinsic denervation was studied in anaesthetised cats, previously subjected to truncal vagotomy and/or coeliacectomy, and compared with sham operated controls. Net water absorption was studied by perfusion techniques. Acute experiments were performed under basal conditions and $\alpha$-adrenoceptor stimulation (intra-arterial infusion of noradrenaline). Gall bladder biopsies were studied by fluorescence microscopy and cytofluorimetry to visualise and quantify catecholamines. Three weeks after coeliacectomy basal absorption had decreased significantly. In the short term vagotomy group no changes were shown. In the long term vagotomy group, however, there was a four-fold increase in absorptive capacity, which decreased to control levels after $\alpha$-adrenoceptor blockade (phentolamine). Long term vagotomy with subsequent coeliacectomy caused no significant changes. Infusion of noradrenaline increased net water absorption by $60 \pm 11 \%$ in all experimental groups except in long term vagotomised animals, where the high basal absorption was not further augmented. One hour after noradrenaline infusion controls returned to basal absorption rate, while denervated cats remained at stimulated levels. In long term vagotomised gall bladders there were morphological signs of adrenergic proliferation (increased total number of nerve terminals, sprouting and raised levels of intraneuronal noradrenaline). These results suggest that the adrenergic nervous system is important for full absorptive capacity of the gall bladder. The increased absorption after long term vagotomy, abolished after $\alpha$-adrenoceptor blockade, might well be explained by the parallel adrenergic proliferation. This hypothesis was further corroborated in animals with long term vagotomy, where subsequent surgical adrenergic denervation restored basal absorption to control levels.

In the classical description the gall bladder receives its extrinsic nerve supply of cholinergic fibres from the left vagal nerve and of adrenergic fibres from the coeliac ganglion. ${ }^{12}$ These sources, however, may also contribute with other types of nerve fibres to the biliary innervation. Both the vagal nerve and the splanchnic complex have been shown to contain axons with several neuropeptides. ${ }^{34}$ The vagal nerve also carries adrenergic nerve fibres, originating from the superior cervical ganglia, stellate ganglia, and thoracic sympathetic ganglia to the upper gastrointestinal tract in this species. ${ }^{56}$ The intrinsic neurones were classically considered to

Address for correspondence: Dr Stellan Björck, Department of Surgery I. Sahlgrenska sjukhuset, S-413 45 Göteborg. Sweden.

Received for publication 2 September 1983 be cholinergic. ${ }^{7}$ In analogy with recent immunohistochemical findings in the gut, ${ }^{34}$ however, intrinsic peptidergic neurones of the gall bladder wall may be expected. Tryptaminergic neurones in the myenteric plexus have recently been shown immunocytochemically, ${ }^{8}$ but their source of origin is still unknown. To further augment this complexity, very little is known about the sensory information from the gastrointestinal tract via these neural pathways. Therefore, vagotomy or coeliacectomy cannot be regarded as producing clearcut extrinsic cholinergic or adrenergic denervation respectively of the gut or biliary tree.

We have already observed that electrical stimulus of the vagus reduced the concentrating ability via a non-cholinergic non-adrenergic mechanism. ${ }^{9}$ Splanchnic activation, however, as well as infusion 
of noradrenaline enhanced this function, ${ }^{11}$ suggesting that the adrenergic innervation stimulates the absorptive capacity of the gall bladder. In the present investigation our aims were to study (a) the effects of vagotomy and coeliacectomy on basal and catecholamine stimulated absorptive function in the gall bladder and (b) the effect of vagotomy on the adrenergic nerve supply to the gall bladder. Therefore, adrenergic nerves were visualised by fluorescence histochemistry according to the Hillarp-Falck technique ${ }^{11}$ and the adrenergic transmitter levels were studied by semiquantitative cytofluorimetry. ${ }^{12}$ As parasympathetic denervation in various organs causes a proliferation of the adrenergic nerve supply and/or a hypersensitivity of adrenoreceptors, ${ }^{13-1}$ we wanted to compare the adrenergic innervation of the feline gall bladder in long term vagotomised animals and controls.

\section{Methods}

\section{ANIMALS}

EXPERIMENTAL PROCEDURES AND EXPERIMENTAL GROUPS

All experiments were performed on cats and the following experimental groups were studied: (1) controls $(n=9)$ - that is, shamlaparotomy cats; (2) cats with truncal vagotomy three weeks before the experiments $(n=6) ;(3)$ cats with truncal vagotomy three months before the experiments $(n=6) ;(4)$ cats with coeliacectomy three weeks before the experiments $(n=6) ;(5)$ cats with truncal vagotomy three months before coeliacectomy, performed three weeks before the experiments $(n=5)$.

Midline thoracotomy was performed. The vagotomy procedure included division of all vagal fibres along the oesophagus from the inferior pulmonary vein down caudally to the diaphragm. Coeliacectomy included excision of the coeliac and superior mesenteric ganglia at laparotomy.

The absorption studies were performed on adult cats of both sexes weighing $2 \cdot 5-5 \cdot 1 \mathrm{~kg}$. The animals were fasted for 24 hours before the experiments but had free access to water. Anaesthesia was induced by ether, and maintained with chloralose $50-100$ $\mathrm{mg} / \mathrm{kg}$ bw intravenously during the experiment. Studies of net water absorption in the gall bladder were performed in all of the five groups described (a) under basal conditions, (b) during stimulation of $\alpha$-adrenoceptors (a steady state was reached after 40-50 minutes), and (c) one hour after such stimulation (intra-arterial infusion of noradrenaline, $1 \mathrm{mg} / \mathrm{kg} / 60$ minutes). All measurements were made at end of infusion (60 minutes). In a separate group of three cats, vagotomised for three months, absorption studies were also performed before and after $\alpha$-adrenoceptor blockade with phentolamine (1 $\mathrm{mg} / \mathrm{kg}$ bw intravenously), injected slowly during five minutes.

\section{NET WATER ABSORPTION STUDIES}

The operative procedures were identical to those described in an earlier paper. ${ }^{1 /}$ In summary the method involves a continuous perfusion of the gall bladder with an isotonic electrolyte solution similar to that of feline hepatic bile $\left(\mathrm{Na}^{+} 135 \mathrm{mmol} / \mathrm{l}, \mathrm{K}^{+} 5\right.$ $\left.\mathrm{mmol} / \mathrm{l}, \mathrm{Cl}^{-} 105 \mathrm{mmol} / \mathrm{l}, \mathrm{HCO}_{3}^{-} 35 \mathrm{mmol} / \mathrm{l}\right)$. Perfusion of the gall bladder with the organ in situ was performed by introduction of catheters into the gall bladder lumen inserted from the fundus of the gall bladder. The cystic duct was ligated with great care so not to injure vessels or nerves. Each of the two catheters were connected to two separate chambers placed on an electromagnetic balance (Grass Force displacement transducer FT 10, Grass Instruments, US). A roller pump (HP4, Ismatec SA, Zürich, Switzerland) kept the circulation at a constant rate of $0.15 \mathrm{ml} / \mathrm{min}$, and the hydrostatic pressure in the gall bladder was set at $7 \mathrm{~cm} \mathrm{H}_{2} \mathrm{O}$ by adjusting the height of the balance. In all the experiments the pylorus was ligated in order to prevent gastric juice from reaching the duodenum.

DETERMINATION OF NET WATER ABSORPTION

${ }^{14} \mathrm{C}$-polyethylene glycol (PEG) (Radiochemical Centre, Amersham, England) was added to the perfusate. The net water transport was calculated from the perfusion rate and the change in concentration of the tracer during its passage through the gall bladder. Details concerning these calculations are discussed in an earlier paper. ${ }^{18}$

MEASUREMENT OF GALL BLADDER VOLUME At the end of each experiment the gall bladder was filled with the perfusate at a hydrostatic gradient of $7 \mathrm{~cm} \mathrm{H}_{2} \mathrm{O}$ (perfusion pressure) to estimate the gall bladder volume.

\section{STATISTICS}

The comparisons of physiological data were performed by analysis of variance (Duncan's method for multiple comparison). ${ }^{19}$

FLUORESCENCE HISTOCHEMISTRY AND CYTOFLUORIMETRY

For this part of the study seven animals were used. Three were controls, and four had had a transthoracic vagotomy three months before death. Three of the vagotomised cats had, before biopsies, been used for absorption studies after $\alpha$ adrenoceptor blockade (phentolamine) at basal conditions. At the end of the experiments the gall 
bladder was extirpated in Ketamine ${ }^{\circledR}$ anaesthesia and biopsies $(2 \times 2 \mathrm{~mm})$ were taken from the neck, body, and fundus of the gall bladder. The small biopsies were placed on coded papers, frozen in liquid propane cooled by liquid nitrogen, and freeze dried at $-45^{\circ} \mathrm{C}$ for three days. After subsequent treatment with paraformaldehyde gas at $80^{\circ} \mathrm{C}$ and paraffin embedding in vacuo, $10 \mu$ sections were cut, placed on glass slides and mounted as previously described ${ }^{11}$ in a mixture of xylene and Entellane ${ }^{\circledR}$. The specimens were examined in a fluorescence microscope equipped for epi-illumination and adjusted to the noradrenaline fluorophore activation wave length $(370 \mathrm{~nm})$.

During the paraformaldehyde treatment catecholamines - for example, noradrenaline - are converted to strongly green fluorescent substances, which can be localised to cellular elements - for example, nerves - in the tissue. The strong yelloworange autofluorescence of bile salts was observed on the luminal side of the tissue sections, but there were no difficulties in distinguishing the specific noradrenaline induced green fluorescence from the bile fluorescence. In doubtful cases it was possible to test the specificity of fluorescence using sodium borohydride. ${ }^{20}$ For cytofluorimetric studies the following procedure was used: in each specimen examined all adrenergic nerve terminals occurring along a line, perpendicular to the longitudinally sectioned gall bladder wall, were visualised by a microscopic scanning technique ${ }^{21}$ (Fig. 1), where each fluorescent terminal was recorded graphically as a peak. During the scanning procedure the section can be observed microscopically, and each peak in fluorescence intensity can be related to a specific structure of fluorophore. Thus, peaks induced by bile salt fluorescence could easily be identified and separated from peaks due to adrenergic nerve terminals. Such scanning was applied to several sections (two-four) from each region (neck, body, fundus) of the gall bladders. This technique allows an approximate measurement of the density of the adrenergic innervation, as both readings of the number of terminals scanned and of the total wall thickness were obtained.

In order to obtain a measurement of the intracellular levels of noradrenaline stored in individual adrenergic nerve terminals cytofluorimetric spot measurements were performed. ${ }^{12}$ Varicose nerve terminals were randomly chosen from coded specimens and positioned into a quadriangular diaphragm $(0.2 \mu \mathrm{m})$ and their emitted fluorescence was recorded photometrically (after activation by ultraviolet light under above filter combinations after 15 seconds to avoid initial photodecomposition of the fluorophore - for details cf 12). Background

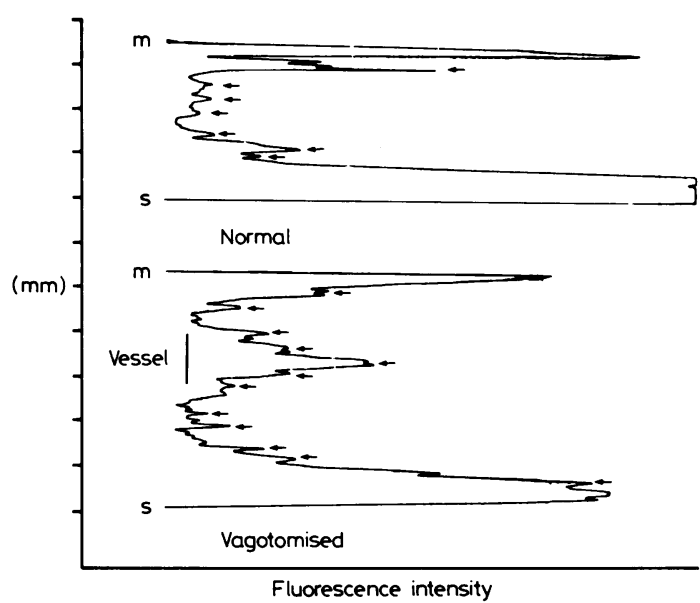

Fig. 1 Microscopic scanning graphs of normal and long term vagotomised gall bladder walls. Transverse tissue sections, prepared for fluorescence microscopy (see text), were scanned along a perpendicular line from mucosa $(m)$ to the serosa (s) (cf Fig. 3) at constant rate of $5 \mathrm{~mm} / \mathrm{min}$ under measuring diaphragm $(0 \cdot 2 \times 0.2 \mu \mathrm{m})$. During scan the catecholamine fluorophore was activated by ultraviolet light under optimal filter combinations. Emitted fluorescence was continuously recorded through diaphragm by photometric recording system. In normal gall bladder several adrenergic terminals were scanned and shown as peaks of increased fluorescence (arrows). Initial major peak at mucosal end $(m)$ of the specimen represents fluorescence due to bile in the lumen, while the final major peak at serosal end (s) represents autofluorescence in the serosa (cf Fig. 3). After vagotomy an increased total number of adrenergic nerve terminals $(n=12)$ were shown in the gall bladder wall compared with controls $(n=7)$, accompanied by an increased wall thickness $(1.75 \rightarrow 2.75 \mathrm{~mm})$, why the relative density of adrenergic nerve terminals per $\mathrm{mm}$ was unchanged $(4 \cdot 0 \rightarrow 4 \cdot 4)$.

fluorescence (from an adjacent area without adrenergic terminals) was similarly recorded and subtracted from the nerve terminal reading. Such readings of fluorescence intensity are proportional to the intracellular levels of noradrenaline in individual adrenergic nerve terminals. ${ }^{21}$ One hundred recordings each from three controls and four long term vagotomised animals were processed in a Hewlett-Packard computer and statistically compared using Student's $t$ test.

\section{Results (Table)}

STUDIES OF NET WATER TRANSPORT

Group no 1: controls

In nine cats there was an average increase in net water absorption by $72 \%$ in response to an intra- 
Table Net water absorption $\mathrm{ml} / \mathrm{h}( \pm S E)$

\begin{tabular}{|c|c|c|c|}
\hline & $\begin{array}{l}\text { Basal } \\
\text { absorption }\end{array}$ & $\begin{array}{l}\text { Absorption during } \\
\text { noradrenaline } \\
\text { infusion }\end{array}$ & $\begin{array}{l}\text { Absorption } \\
\text { one hour after } \\
\text { noradrenaline } \\
\text { infusion }\end{array}$ \\
\hline \multicolumn{4}{|l|}{ Group $1(n=9)$} \\
\hline Control & $0 \cdot 50 \pm 0 \cdot 11$ & $0.93 \pm 0.11 \dagger$ & $0 \cdot 64 \pm 0 \cdot 15^{*}$ \\
\hline \multicolumn{4}{|l|}{ Group $2(n=6)$} \\
\hline Vagotomy, three weeks & $0.69 \pm 0.16$ & $1.02 \pm 0.22$ & $0.74 \pm 0.23$ \\
\hline \multicolumn{4}{|l|}{ Group $3(n=6)$} \\
\hline Vagotomy, three months & $2.03 \pm 0.40 \ddagger$ & $2 \cdot 10 \pm 0 \cdot 41 \ddagger$ & $2 \cdot 09 \pm 0.46 \ddagger$ \\
\hline \multicolumn{4}{|l|}{ Group $4(n=6)$} \\
\hline Coeliacectomy, three weeks & $0.33 \pm 0.04 \ddagger$ & $0.49 \pm 0.07^{*}$ & $0.47 \pm 0.24$ \\
\hline \multicolumn{4}{|l|}{ Group $5(n=5)$} \\
\hline $\begin{array}{l}\text { Vagotomy, three months }+ \\
\text { coeliacectomy, three weeks }\end{array}$ & $0.70 \pm 0.66$ & $1 \cdot 14 \pm 0.45$ & $1.33 \pm 0.48^{*}$ \\
\hline
\end{tabular}

Net water absorption studied for 60 minutes in each period by the perfusion technique described. In all groups three periods were studied: basal absorption, absorption during $\alpha$-adrenoceptor stimulation, and absorption one hour after cessation of stimulation. Significant differences from basal periods in each group: ${ }^{*} p<0.05,+p<0.005$.

$\ddagger$ Periods significantly different from group 1 (controls) at $\mathrm{p}<0.05$.

arterial infusion of noradrenaline into the coeliac axis during 60-90 minutes. The blood pressure increased by $21 \pm 3 \mathrm{~mm} \mathrm{Hg}$. After the infusion was stopped the water absorption decreased to prestimulatory level. Gall bladder volume was estimated to be $2 \cdot 34 \pm 0 \cdot 12 \mathrm{ml}(\mathrm{SE})$.

\section{Group no 2: vagotomy, three weeks}

Six experiments were performed. The net water absorption under basal conditions and during the infusion of noradrenaline did not differ significantly. Gall bladder volume was estimated to be $2.95 \pm 0.41$ $\mathrm{ml}$ (SE).

Group no 3: vagotomy, three months

Six experiments were performed. Under basal conditions the absorption rate was increased fourfold compared with the control group. The absorption rate was not, however, further augmented by infusion of noradrenaline, and remained at a high level after noradrenaline infusion. Gall bladder volume was estimated to be $3.05 \pm 0.33 \mathrm{ml}(\mathrm{SE})$.

Group no 4: coeliacectomy, three weeks

Six experiments were performed. The basal absorption rate was significantly decreased compared with controls and infusion of noradrenaline caused a significant increase that persisted one hour after the interruption of noradrenaline infusion.

Group no 5: vagotomy and coeliacectomy

Five animals were studied. The basal rate of absorption was in the same range as in controls, but different from the absorption in animals with vagotomy alone (group 3). Infusion with noradrenaline caused no significant increase in absorption.

\section{Vagotomy and $\alpha$-adrenoceptor blockade}

Three animals were studied three months after vagotomy. After a control period when high absorption, similar to group 3, was recorded, phentolamine $1 \mathrm{mg} / \mathrm{kg}$ intravenously was given over a five minute period. The net water absorption in the gall bladder was determined over the next 60 minutes and in all three animals there was a marked decrease in absorption (by $80 \%$ ) (see Fig. 2).

\section{Histochemical studies}

In control cats the formaldehyde induced green fluorescence was localised to abundant adrenergic nerve fibres, distributed to mainly the muscle layer and the vessels. Also in the mucosa adrenergic nerve fibres were seen (Fig. 3). In vagotomised animals there was a prominent thickening of the wall of the gall bladder, especially of the lamina propria. An increased folding of the mucosa was also noticed, but not measured morphologically. In vagotomised animals studied the total wall thickness was twice that of controls (Figs 1,3). There was no evident oedema in the wall, but minor inflammatory reaction as indicated by the presence of moderate round cell hyperplasia in the propria. There was an increase in the total number of adrenergic nerve terminals. In the lamina propria the total number of thin adrenergic nerve terminals of moderate fluorescence intensity appeared increased, but the density of such terminals was unchanged (Figs 1, 3). 


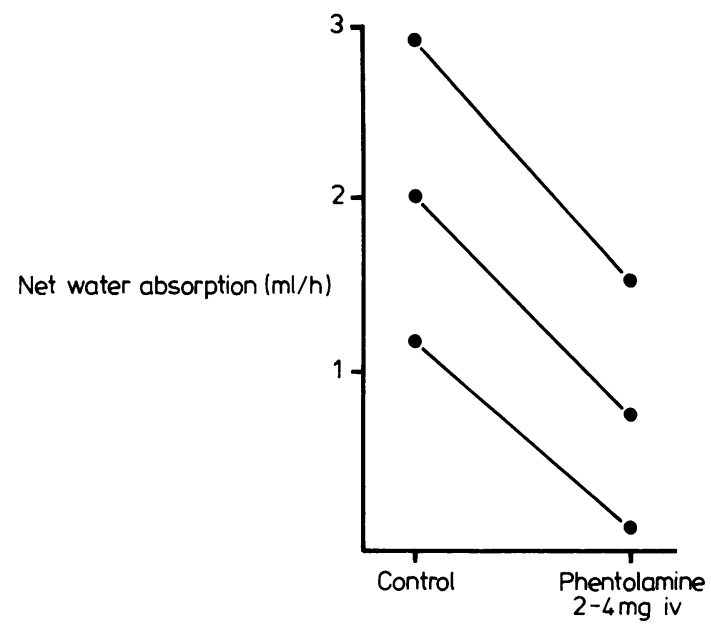

Fig. 2 Three cat experiments, three months after truncal vagotomy, where net water transport has been studied before and after administration of phentolamine (total dose indicated) during basal conditions.

The adrenergic nerve terminals in the smooth muscle layer were larger in diameter and more strongly fluorescent. In the microscope scanning studies there was no significant increase in the density of adrenergic innervation, as the increased number of adrenergic terminals was accompanied by an increased wall thickness as seen in Fig. 1.

The adrenergic varicosities showed an increased fluorescence intensity in the long term vagotomised group in all locations studied (neck, body, fundus). In one of these animals a few characteristic growth cones were observed indicating adrenergic sprouting.

When the fluorescence intensity of individual varicosities, randomly chosen, was studied cytofluorimetrically in coded biopsies, there was a $66 \%$ increase in fluorescence intensity $(p<0.05)$ in long term vagotomised animals $(n=100)$ as compared with control animals $(n=100)$.

\section{Discussion}

In the present study the effects of denervation on the absorptive function of gall bladders were studied by a perfusion technique in anaesthetised cats. In the steady state situation it was found that truncal vagotomy three weeks earlier had no influence on water absorption, but in long term (three months) vagotomised animals a marked increase in the net water absorption had occurred (Table). In contrast, three weeks after coeliacectomy a significant decrease in net water transport compared with

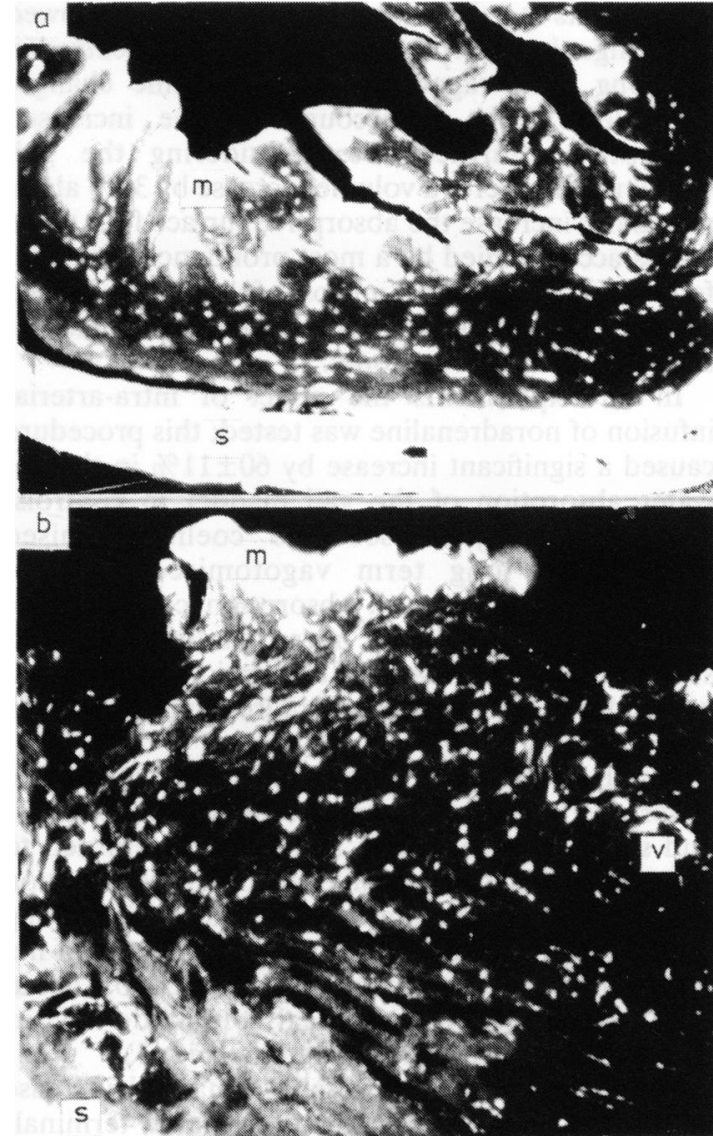

Fig. 3 Fluorescence micrographs of longitudinal sections of gall bladder wall from (a) normal animal and (b) long term vagotomised animal. Numerous green fluorescent adrenergic nerve terminals were seen around vessels in the mucosa $(m)$ and muscle layers. Non-specific fluorescence (not due to the presence of catecholamine) was seen in the serosal layer $(\mathrm{s})$ and at top of the mucosa $(\mathrm{m})$ (due to the presence of bile). Note prominent thickening of the gall bladder wall and the increased number of adrenergic nerve terminals in vagotomised gall bladder $(\times 40$, original magnification). $V$ indicates adrenergic terminals around $a$ vessel.

controls was seen. In animals with vagotomy and subsequent coeliacectomy it was found that the absorption of water was somewhat higher than in controls, but significantly less than in animals with long term vagotomy only.

In vagotomised animals there was a significant decrease in gall bladder tone already after three weeks, reflected by a $30 \%$ increase of gall bladder volume, which persisted in long term vagotomised 
animals. As the short term vagotomy group showed no changes in absorptive capacity, which occurred in the long term vagotomy group, volume changes seem less likely to account for the increased absorption. Furthermore, considering the gall bladder as a sphere, a volume increase by $30 \%$ alone would not increase the absorptive surface four times unless accompanied by a most pronounced mucosal folding. A pronounced mucosal folding was indeed observed, but appeared fully developed already at three weeks after vagotomy.

In all experiments the effect of intra-arterial infusion of noradrenaline was tested; this procedure caused a significant increase by $60 \pm 11 \%$ in the net water absorption of the gall bladder in controls, short term vagotomised and coeliacectomised animals. In long term vagotomised animals, however, the high basal absorption could not be further augmented by noradrenaline infusion, suggesting that the maximal absorption capacity was reached already before the noradrenaline infusion in these animals.

One hour after the infusion of noradrenaline the absorptive pattern was again studied. Only controls and short term vagotomy animals had returned to basal absorptive rate, while all other denervation groups remained at stimulated levels. In three long term vagotomised animals the high basal rate of net water transport was efficiently reduced by about $80 \%$ after pharmacological blockade of $\alpha$ adrenoceptors using phentolamine (Fig. 3).

Fluorescence histochemically a marked increase in the total number of adrenergic nerve terminals in the thickened gall bladder walls was observed in the long term vagotomy group. The cytofluorimetric data also showed a substantial increase of the adrenergic transmitter levels in individual varicosities, as reflected by an increased fluorescence intensity. A few typical growth cones, indicating a sprouting of the terminals, were observed in one cat. These results corroborate the findings of Tsurumi and Onda, ${ }^{22}$ who described a marked proliferation of adrenergic nerve terminals in all layers of the gall bladder wall in patients after gastrectomy, a procedure that probably had severed the vagal fibres to the gall bladder. In parasympathetically denervated cat urinary bladders adrenergic growth cones were observed three to six weeks after denervation, but not three to four months later. This fact would probably explain why growth cones were rarely seen in the long term vagotomised cats.

The present model has earlier been used to show the presence of an $\alpha$-adrenergic mechanism causing an increased net water absorption in acute nerve stimulation experiments. ${ }^{10}$ Field and $\mathrm{McColl}^{23}$ and Hubel $^{24}$ have shown in vitro and in vivo, respectively, a similar increase in net water uptake in the small intestine in rabbits and rats upon $\alpha$-adrenergic stimulation. Furthermore, Brunsson et $a l^{25}$ reported that electrical stimulation of the splanchnic nerves in cats caused an increase in jejunal water absorption. Kreis and Fordtran ${ }^{26}$ suggested that such $\alpha$-adrenoceptor stimulation enhances active sodium and chloride absorption in the gut epithelium by an increase in mucosal cell cGMP. In the gall bladder it was also shcwn in vitro that an increase in intracellular cAMP reduced the fluxes of sodium and chloride into the mucosal cells. ${ }^{27}$

The present observation of a decrease in net water absorption in the gall bladder after coeliacectomy may be because of a decreased adrenergic nerve supply to the mucosa. A total sympathetic denervation is difficult to achieve by surgical methods owing to the contribution of adrenergic fibres from the vagus and from paravascular nerve bundles not originating from the mesenteric ganglia. ${ }^{28}$ Although Baumgarten $e t a l^{2}$ had shown a reduction of adrenergic innervation of the biliary tree after excision of the coeliac and superior mesenteric ganglia, the increase in water absorption after vagotomy suggests that either a normal inhibitory mechanism has been lost or there has been an increased sensitivity to stimulation. The histochemical evidence of increased adrenergic innervation three months after vagotomy together with an enhanced basal water absorption which can be blocked by phentolamine, suggest that an $\alpha$-adrenoceptor mediated mechanism is responsible for the increased absorption in these vagotomised animals. The increase in fluorescence intensity of varicose nerve terminals ${ }^{12}$ is less likely due to intrinsic effects of phentolamine, as it was also observed in the untreated animal with long term vagotomy.

Such enhanced sensitivity might operate via several mechanisms known from other tissues: (1) An increased number and/or an increased sensitivity of $\alpha$-adrenoceptors postvagotomy. Such changes of $\alpha$-adrenoceptors were described to occur in the feline urinary bladder six weeks after parasympathetic denervation. ${ }^{14}$ In histochemical studies an increased adrenergic innervation and sprouting was also found. ${ }^{13} 1516$ Although frequent growth cones were shown in the urinary bladder at six weeks after parasympathetic denervation, they decreased thereafter and were not seen three to four months postoperatively. This may explain the sparse occurrence of growth cones in the present study. Sprouting has also been reported in the central nervous system after cholinergic denervation of the habenular complex. ${ }^{29} \mathrm{~A}$ sensitisation of 
$\alpha$-adrenoceptors following parasympathetic denervation has been shown in the rat parotid gland. ${ }^{17}$ (2) An increased transmitter release from adrenergic terminals. Such an increased release by adrenergic nerve terminals may be owing to loss of inhibition of adrenergic release, which may involve mediation by a variety of transmitter systems (cf 30 for discussion).

In the present study the maximal absorptive function was dependent on the presence of some $\alpha$-adrenoceptor stimulation. Absorption decreased in animals after coeliacectomy, but increased after parasympathetic denervation probably because of increased $\alpha$-adrenoceptor activity. Such an increase in $\alpha$-adrenoceptor activity may be secondary to an increased adrenergic innervation, in analogy to the observations in feline urinary bladder. ${ }^{14}$ The importance of $\alpha$-adrenoceptors was further corroborated in vagotomised animals, where the basal high absorption was dramatically reduced after administration of the $\alpha$-adrenoceptor antagonist phentolamine. The high absorption rate seen in animals subjected to coeliacectomy one hour after cessation of noradrenaline infusion is most likely owing to the removal by denervation of one of the most important inactivation mechanisms of exogenous noradrenaline; the reuptake of the adrenergic transmitter into adrenergic nerves via the membrane pump. The very high rate of absorption in long term vagotomised animals was not influenced by noradrenaline infusion, indicating that the basal rate of absorption in these animals was maximal.

This study was supported by grants from the Swedish MRC (17X-04984, 17X-5220, 04X-2207), from $M$ Bergwalls Foundation, from $T$ and $R$ Söderbergs Foundations, and from $W$ and $M$ Lundgrens Foundation. Monica Wallin and AnnChristin Illerskog are gratefully acknowledged for skilful technical assistance, and Anita Olsson for expert secretarial work.

\section{References}

1 Hirt A. In: Hrsg. von Bolk L, Göppert E, Kallius E, Labosch W., eds. Handbuch der vergleichenden Anatomie der Wirbeltiere, Band 2, Häft 1. Berlin and Wien: Urban and Schwarzenberg, 1934: 735-76.

2 Baumgarten HG, Lange W. Extrinsic adrenergic innervation of the extrahepatic biliary duct system in guinea-pigs, cats and rhesus monkeys. Z Zellforsch 1969; 100: 606-15.

3 Lundberg JM, Hökfelt T, Nilsson G et al. Peptide neurons in the vagus, splanchnic and sciatic nerves.
Acta Physiol Scand 1978; 104: 499-501.

4 Furness JB, Costa M. Types of nerves in the enteric nervous system. Neuroscience 1980; 5: 1-20.

5 Muryobayashi TJ, Fujiwara $M$, Shimamoto $\mathrm{K}$. Fluorescence histochemical demonstration of adrenergic nerve fibres in the vagus nerve of cats and dogs. Jpn J Pharmacol 1968; 18: 285-93.

6 Ahlman BHJ, Larson GM, Bombeck CT, Nyhus LM. Origin of the adrenergic nerve fibres in the subdiaphragmatic vagus in the dog. Am J Surg 1979; 137: 116-22.

7 Jacobowitz D. Histochemical studies of the autonomic innervation of the gut. J Pharmacol Exp Ther 1965; 149: $358-64$.

8 Dahlström A, Ahlman H. Immunocytochemical evidence for the presence of tryptaminergic nerves of blood vessels, smooth muscle and myenteric plexus in the rat small intestine. Acta Physiol Scand 1983; 117: 589-91.

9 Björck S, Jansson R, Svanvik J. Influence of electrical vagal stimulation and acetylcholine on the function of the feline gallbladder. Scand J Gastroenterol 1983; 18: 129-35.

10 Björck $S$. The adrenergic influence on concentrating function in the feline gallbladder. Gut 1982; 23: 1019-23.

11 Corrodi $\mathrm{H}$, Jonsson $\mathrm{G}$. The formaldehyde fluorescence method for the histochemical demonstration of biogenic monoamines. J Histochem Cytochem 1967; 15: 65-78.

12 Ahlman H. Fluorescence histochemical studies on serotonin in the small intestine and the influence of vagal nerve stimulation. Acta Physiol Scand 1976; suppl 437: $1-30$.

13 Sundin T, Dahlström A. The sympathetic innervation of the urinary bladder and urethra in the normal state and after parasympathetic denervation at the spinal root level. Scand J Urol Nephrol 1973; 7: 131-49.

14 Norlén L, Dahlström A, Sundin T, Svedmyr N. The adrenergic innervation and adrenergic receptor activity of the feline urinary bladder and urethra in the normal state and after hypogastric and/or parasympathetic denervation. Scand J Urol Nephrol 1976; 10: 177-84.

15 Sundin T, Dahlström A, Norlén L, Svedmyr N. The sympathetic innervation and adrenoreceptor function of the human lower urinary tract in the normal state and after parasympathetic denervation. Investig Urol 1977; 14: 322-8.

16 Dahlström A. The adrenergic innervation of the urinary bladder in the cat and man in the normal state and after parasympathetic denervation. Acta Pharmacol Toxicol 1978; 43: 19-25.

17 Ekström J. Sensitization of the rat parotid gland secretagogues following either parasympathetic denervation, sympathetic denervation or decentalization. Acta Physiol Scand 1980; 108: 253-61.

18 Svanvik J, Jansson R. An experimental method for studying in vivo gallbladder absorption. Gastroenterology 1977; 72: 634-8.

19 Duncan DB. Multiple range and multiple F-tests. Biometrika 1955; 11: 1-42.

20 Corrodi H, Hillarp N-Ä, Jonsson G. Fluorescence 
methods for histochemical demonstration of monoamines. 3. Sodium borohydride reduction of the fluorescent compounds as a specificity test. $J$ Histochem Cytochem 1964; 12: 582.

21 Jonsson G. Quantitation of fluorescence of biogenic monoamines, demonstrated with the formaldehyde fluorescence method. Stuttgart: Gustav Fischer Verlag, 1971: 1-15.

22 Tsurumi K, Onda M. A fluorescence histochemical study for the motility of the gallbladder. Gastroenterol Jpn 1979; 44: 147-54.

23 Field M, McColl I. Ion transport in rabbit ileal mucosa. Effects of catecholamines. Am J Physiol 1973; 225: 852-7.

24 Hubel KA. Intestinal ion transport: effects of norepinephrine, pilocarpine and atropine. Am J Physiol 1976; 231: 252-7.

25 Brunsson I, Eklund S, Jodal M et al. The effect of vasodilatation and sympathetic nerve activation on net water absorption in the cat small intestine. Acta Physiol Scand 1979; 106: 61-8.

26 Kreis GJ, Fordtran IS. Physiology and pathophysiology of ion and water movement on the human intestine. In: Sleisenger MH, Fordtran JS, eds. Gastrointestinal disease. Philadelphia, London, Toronto: Saunders Company, 1978: 297-313.

27 Frizzell AR, DuGass MC, Schultz SG. Sodium chloride transport by rabbit gallbladder: direct evidence for a coupled $\mathrm{NaCl}$ influx process. J Gen Physiol 1975; 65: $769-95$.

28 Larson G, Ahlman H, Bombeck CT, Nyhus LM. Gastric acid secretion after chemical sympathectomy. Surgery 1979; 85: 534-42.

29 Crutcher KA, Davis JN. Noradrenergic sprouting in response to cholinergic denervation: the sympathohabenular connection. Exp Neurol 1980; 70: 187-91.

30 Westfall TC. Local regulation of adrenergic neurotransmission. Physiol Rev 1977; 57 (4): 659-728. 